\title{
Intratumoral Injection of H101 in Combination With Concurrent Chemoradiotherapy for Locally Advanced Cervical Cancer
}

Xiang Zhang

Zhejiang Cancer Hospital

Yingchang Wang

Zhejiang Cancer Hospital

xiaojuan Lv

Zhejiang Cancer Hospital

Fangfang Wang

Zhejiang Cancer Hospital

Qiong Zhou

Zhejiang Cancer Hospital

Feiya Zhang

Zhejiang Cancer Hospital

Meng Zhang

Zhejiang Cancer Hospital

Jianhong Chen ( $\square$ chenjh@zjcc.org.cn )

Zhejiang Cancer Hospital

\section{Research}

Keywords: Cervical cancer, Concurrent chemoradiotherapy, Oncolytic virus, Survival, Safety

Posted Date: September 3rd, 2021

DOl: https://doi.org/10.21203/rs.3.rs-858111/v1

License: (1) (1) This work is licensed under a Creative Commons Attribution 4.0 International License.

Read Full License 


\section{Abstract}

\section{Background}

To evaluate the clinical benefit of concurrent chemoradiotherapy in combination with $\mathrm{H} 101$ injection for the treatment of locally advanced cervical cancer (LACC) patients.

\section{Methods}

The patients, all diagnosed with stage IIB or III cervical cancer according to The International Federation of Gynecology and Obstetrics (FIGO) stage (2009) with tumor length $\geq 6 \mathrm{~cm}$ were enrolled at Zhejiang Cancer Hospital from July 2015 to April 2017. All patients received concurrent chemoradiotherapy (CCRT) in combination with intratumoral H101 injection before and during external beam radiotherapy (EBRT). The parameters recorded and analyzed included progression-free survival (PFS), overall survival (OS), tumor regression after EBRT and side effects, which were compared to another group of patients with similar characteristics treated with CCRT alone.

\section{Results}

Twenty patients were treated with CCRT in combination with intratumoral $\mathrm{H} 101$ injection and another group of 20 patients treated with CCRT alone was selected as control. The median follow-up time was 38 months (range 10-58 months). The 3-year local, regional, and overall PFS rates were $95 \%$ vs $66.6 \%(p=$ $0.02), 95 \%$ vs $62.5 \%(p=0.029)$, and $65 \%$ vs $43.8 \%(p=0.19)$, for $\mathrm{H} 101$ group and control group respectively. The 3-year (OS) was $74.3 \%$ vs $54.5 \%(p=0.098)$, respectively. The median reduction of tumor length and volume for $\mathrm{H} 101$ group and control group were $37.7 \%$ vs $28.7 \%(\mathrm{p}=0.016)$ and $75.1 \%$ vs $62.4 \%(p=0.001)$, respectively. The major adverse event related to $\mathrm{H} 101$ was fever.

\section{Conclusion}

CCRT in combination with intratumoral H101 injection is effective in treating LACC, and has an acceptable safety profile.

\section{Trial registration}

The study was registered at Chinese Clinical Trail Registry (ChiCTR-OPC-15006142).

\section{Background}

In 2018, cervical cancer, which is globally the fourth most common cancer in women, accounted for approximately 570,000 newly diagnosed cervical cancer cases and about 300,000 deaths [1]. Although the incidence and mortality of cervical cancer have declined over the past few decades in developed countries with the implementation of organized cervical screening and HPV vaccination programs [2], this 
type of cancer, especially locally advanced cervical cancer (LACC) still constitutes a major public health concern in developing countries [1, 2].

Concurrent chemoradiotherapy (CCRT), including brachytherapy (BT), has been well-established as the standard treatment for LACC [3]. Although CCRT has proved to improve the outcome of LACC compared with radiotherapy alone, the high recurrence rate and a low survival rate of LACC necessitates the pursuit of new treatment strategies.

H101 (Oncorine), produced by Shanghai Sunway Biotech (Shanghai, China), is an oncolytic recombinant human type 5 adenovirus, in which the entire E1B-55kDa gene and a $19 \mathrm{kDa}$ segment of the E3 region have been deleted. H101 was approved by the Chinese Food and Drug Administration (CFDA) for combination with chemotherapy for the treatment of nasopharyngeal carcinoma in November 2005 [4].

Several studies have demonstrated the clinical efficacy of H101. A study on the combination of H101 intratumoral injection, radiotherapy, and chemotherapy for the treatment of nasopharyngeal carcinoma showed good antitumor effects and safety [5]. Treatment with $\mathrm{H} 101$ has also been applied as monotherapy or in combination with chemotherapy for liver cancer, lung cancer and pancreatic cancer $[6-11]$.

Nonetheless, few studies have focused on the effects of $\mathrm{H} 101$ for the treatment of cervical cancer, especially in combination with CCRT for radical treatment. This study therefore aimed to evaluate the efficacy and safety of intratumoral H101 injection in combination with CCRT for treating LACC patients.

\section{Methods}

\section{Patient recruitment process}

LACC patients who were admitted to Zhejiang Cancer Hospital from July 2015 to April 2017 with tumor length $\geq 6 \mathrm{~cm}$ were continuously enrolled in this study. The inclusion criteria included (1) histopathologically confirmed cervical cancer (squamous cell carcinoma, adenocarcinoma or adenosquamous carcinoma), (2) treatment-naïve, (3) the maximum diameter of tumor $\geq 6 \mathrm{~cm}$ by computed tomography (CT) imaging, (4) 18-65 years of age, (5) Karnofsky score $\geq 60$, (6) no blood or coagulation disorders present, (7) no severe dysfunction of vital organs including heart, lung, liver, and kidney present, and (8) tolerance to concurrent chemoradiotherapy. Patients that had other uncured malignant tumors, uncontrolled active infection, acquired or congenital immunodeficiency diseases, a history of allergies to biological agents, a history of organ transplantation, those who were pregnant, lactating, or taking antiviral or targeted drugs, and those that had taken high-dose glucocorticoids or other immunosuppressants within a month were excluded. The study was conducted in accordance with the Declaration of Helsinki and Good Clinical Practice, approved by the Ethics Committee of Zhejiang Cancer Hospital. Trial registration: Chinese Clinical Trail Registry, ChiCTR-OPC-15006142. Registered 01 March 2015, https://www.chictr.org.cn/showproj.aspx?proj=10628. All participating patients gave their written informed consent for taking part in the study. 
This study was initially designed as a prospective, single arm trial. To access the efficacy of CCRT in combination with $\mathrm{H} 101$, another group of 20 patients with tumor length $\geq 6 \mathrm{~cm}$ treated with CCRT alone in the same period was selected as control group.

\section{Intervention}

On day 1, H101 was injected into each of the four quadrants of the cervical tumor with a total amount of $1.5^{\star} 10^{\wedge} 12$ VP in $5 \mathrm{~mL}$ normal saline (NS). On day 4, H101 was injected again into each of the four quadrants of the primary tumor with a total amount of $1.0^{\star} 10^{\wedge} 12 \mathrm{VP}$ ng in $5 \mathrm{~mL}$ NS. CCRT was initiated on day 5. Each patient received external beam radiation therapy (EBRT) followed by BT. When common iliac lymph node and/or paraaortic lymph node metastases were detected, the paraaortic lymph node region was included in the target volume of radiation. For lesions that extended to the lower third of the vagina, the inguinal lymph node region was included in the target volume of radiation. The dose was 4546.8Gy with 25-26 fractions for EBRT, with a concurrent or subsequent boosted dose for metastatic lymph nodes. BT was performed following EBRT, with a prescription dose of 25-30Gy in 5-6 fractions at point A. In cases of lower vaginal invasion, BT of 20-25Gy was applied at $0.5 \mathrm{~cm}$ under the vagina mucosa to boost the dose to the vagina. Concurrent chemotherapy of weekly $40 \mathrm{mg} / \mathrm{m}^{2}$ cisplatin was initiated from day 5. After 21 days (3 weeks), the patients entered another $\mathrm{H} 101$ treatment cycle, and were not allowed to receive any other anticancer or antiviral drugs during the rest of the treatment period.

\section{Assessments}

The patients underwent chest, upper abdominal and pelvic CT scanning, as well as bilateral supraclavicular and inguinal ultrasound examination prior to EBRT, after EBRT, and three months after the end of treatment period. The patients also underwent routine hematological (twice a week) and blood biochemical (once a week) tests, and were tested for gynecological tumor markers throughout the treatment period. After the treatment was completed, follow-up examinations were performed, including pelvic examination, imaging and laboratory tests at 1 month, 3 months, and every 3 months afterwards.

Progression-free survival (PFS) was defined as the time from the start of $\mathrm{H} 101$ treatment to disease progression or death from any cause, whichever came first. Overall survival (OS) was defined as the time from the start of H101 treatment to death from any cause. Adverse effects (AEs) were recorded and graded according to The National Cancer Institute Common Terminology Criteria for Adverse Events, version 5.0 .

Tumor regression was calculated according to the changes of tumor length and tumor volume. Tumor length was defined as the greatest longitudinal dimension on the CT image. Tumor volume was calculated automatically by countering the tumor in a treatment planning system (Pinnacle version 9.1).

\section{Statistical analysis}


Statistical analysis was performed using SPSS 24.0. The continuous variables were presented as medians (ranges), and the categorical variables were displayed as frequencies (percentages). The survival curves were plotted using the Kaplan-Meier method. The $95 \%$ confidence interval (Cl) of the survival rate was estimated as a mean cumulative survival rate $\pm(1.96 \times$ standard error).

\section{Results}

\section{Patient baseline characteristics}

From the total of 23 LACC enrolled patients, three did not receive the treatment due to $\mathrm{H} 101$ delivery issues (Fig. 1), therefore, 20 patients were finally included in the analysis. The patient baseline demographic and clinical characteristics are comparable to the control group and shown in Table 1. 
Table 1

Patient baseline demographic and clinical characteristics

\begin{tabular}{|c|c|c|c|}
\hline Characteristics & $\begin{array}{l}\text { H101 group }(n= \\
20)\end{array}$ & $\begin{array}{l}\text { Control group }(n= \\
\text { 20) }\end{array}$ & $p$ value \\
\hline Age (years), average (range) & $50(38-61)$ & $51.4(32-64)$ & 0.573 \\
\hline \multicolumn{4}{|l|}{ ECOG performance status, n (\%) } \\
\hline 0 & $16(80)$ & 14(70) & \\
\hline 1 & $4(20)$ & $6(30)$ & 0.465 \\
\hline \multicolumn{4}{|l|}{ FIGO Stage 2009, n (\%) } \\
\hline IIB & $9(45)$ & 10(50) & \\
\hline IIIA & $1(5)$ & $1(5)$ & \\
\hline IIIB & $10(50)$ & $9(45)$ & 0.949 \\
\hline \multicolumn{4}{|l|}{ Lymph node involvement, n (\%) } \\
\hline None & $5(25)$ & $4(20)$ & \\
\hline Pelvic & $11(55)$ & $12(60)$ & \\
\hline Paraaortic \pm Pelvic & $4(20)$ & $4(20)$ & 0.926 \\
\hline Lower vaginal invasion, n (\%) & $3(15)$ & 2(10) & 0.633 \\
\hline Squamous cell carcinoma, n (\%) & $20(100)$ & $20(100)$ & \\
\hline \multicolumn{4}{|l|}{ Differentiation, n (\%) } \\
\hline Moderate & $5(25)$ & $7(35)$ & \\
\hline Poor & $6(30)$ & $5(25)$ & \\
\hline Unknown & $9(45)$ & $8(40)$ & 0.597 \\
\hline SCCA (ng/mL), average (range) & $17(1.2-70)$ & 18.1(1.1-70) & 0.127 \\
\hline $\begin{array}{l}\text { HB before treatment }(\mathrm{g} / \mathrm{dL}) \text {, average } \\
\text { (range) }\end{array}$ & 10.6(7.3-13.6) & $10(6.9-13.1)$ & 0.320 \\
\hline $\begin{array}{l}\text { ECOG, the Eastern Cooperative Onco } \\
\text { Obstetrics; SCCA, squamous cell car }\end{array}$ & $\begin{array}{l}\text { p; FIGO, the Intern } \\
\text { ntigen. }\end{array}$ & al Federation of Gyr & gy and \\
\hline
\end{tabular}

\section{Treatment regimes}

The applied treatment regimens are presented in Table 2. In H101 group, all patients completed two cycles of $\mathrm{H} 101$ intratumoral injection and completed CCRT with a median of 5 (range 3-6) cycles of concurrent cisplatin chemotherapy. In 12 cases (60\%), EBRT involved the pelvic only, and in the other 8 
cases $(40 \%)$, EBRT was extended to the paraaortic $(n=5)$ or inguinal $(n=2)$ regions, or both $(n=1)$. All patients received intracavitary BT. The median dose for Point A was 30Gy (range 25-35Gy). In control group, all patients completed CCRT with a median of 5 (range 3-6) cycles of concurrent cisplatin chemotherapy. In 14 cases (70\%), EBRT involved the pelvic only, and in the other 6 cases (30\%), EBRT was extended to the paraaortic $(n=4)$ or inguinal $(n=1)$ regions, or both $(n=1)$. All patients received intracavitary BT. The median dose for Point A was 30Gy (range 25-35Gy). These data were comparable between two groups.

Table 2

Treatment regimes

\begin{tabular}{|lll|}
\hline Variables & $\begin{array}{l}\text { H101 group } \\
(\mathbf{n = 2 0})\end{array}$ & $\begin{array}{l}\text { Control group } \\
(\mathbf{n = 2 0})\end{array}$ \\
\hline Region of EBRT, $\mathbf{n}(\%)$ & $12(60)$ & $14(70)$ \\
\hline Pelvic & $5(25)$ & $4(20)$ \\
\hline Pelvic/Paraaortic & $2(10)$ & $1(5)$ \\
\hline Pelvic/Inguinal & $1(5)$ & $1(5)$ \\
\hline Pelvic/Paraaortic/Inguinal & $45(45-46.8)$ & $45(45-46.8)$ \\
\hline Dose of EBRT (Gy, region), median (range) & $18.9(7.8-20)$ & $19.6(7.2-20)$ \\
\hline Dose of EBRT (Gy, lymph node boost), median (range) & $30(25-35)$ & $30(25-35)$ \\
\hline Dose of Point A (Gy), median (range) & $5(3-6)$ & $5(3-6)$ \\
\hline Total number of chemotherapy, median (range) & & \\
\hline EBRT, external beam radiation therapy. & & \\
\hline
\end{tabular}

\section{Survival}

As of December 2020, the median follow-up time was 38 (10-58) months. The 3-year local, regional, distant and overall PFS rates were $95 \%$ vs $66.6 \%(p=0.02), 95 \%$ vs $62.5 \%(p=0.029), 74.4 \%$ vs $57.6(p=$ $0.428)$ and $65 \%$ vs $43.8 \%(p=0.19)$, for $\mathrm{H} 101$ group and control group respectively. The 3-year overall survival (OS) for $\mathrm{H} 101$ group and control group were $74.3 \%$ vs $54.5 \%(p=0.098)$, respectively. (Fig. 2$)$. By the end of the follow-up period, seven patients in H101 group had shown disease progression, with the failure sites of pelvic lymph node $(n=1)$, supraclavicular lymph node $(n=2)$, lung $(n=2)$, bone $(n=1)$ and vaginal introitus $(n=1)$.

\section{Tumor regression}


The tumor response results are summarized in Table 3. For H101 group, the median tumor length was reduced from $6.6 \mathrm{~cm}$ (range 6-7.3 $\mathrm{cm}$ ) before treatment to $4.1 \mathrm{~cm}$ (range 2.2-5.5 $\mathrm{cm}$ ) after EBRT and the median tumor volume was reduced from $88.35 \mathrm{~cm}^{3}$ (range $41.2-126 \mathrm{~cm}^{3}$ ) before treatment to $20.8 \mathrm{~cm}^{3}$ (range 11.1-47.4 $\mathrm{cm}^{3}$ ) after EBRT. For control group, the median tumor length was reduced from $6.5 \mathrm{~cm}$ (range 6-7.3 $\mathrm{cm}$ ) before treatment to $4.6 \mathrm{~cm}$ (range 3.9-6.1 cm) after EBRT and the median tumor volume was reduced from $86.8 \mathrm{~cm}^{3}$ (range $37.9-188.2 \mathrm{~cm}^{3}$ ) before treatment to $33.2 \mathrm{~cm}^{3}$ (range $18.9-109.1 \mathrm{~cm}^{3}$ ) after EBRT. The median reduction of tumor length and volume for $\mathrm{H} 101$ group and control group were $37.7 \%$ vs $28.7 \%(p=0.016)$ and $75.1 \%$ vs $62.4 \%(p=0.001)$, respectively.

Table 3

Tumor response

\begin{tabular}{|llll|}
\hline Variable & $\begin{array}{l}\text { H101 group } \\
(\mathbf{n = 2 0})\end{array}$ & $\begin{array}{l}\text { Control group } \\
(\mathbf{n = 2 0})\end{array}$ & p value \\
\hline Maximum diameter of tumor, median (range) & & & \\
\hline Before treatment (cm) & $6.6(6-7.3)$ & $6.5(6-7.3)$ & 0.303 \\
\hline Before BT (cm) & $4.1(2.2-5.5)$ & $4.6(3.9-6.1)$ & 0.035 \\
\hline Reduction (\%) & $37.7(8.3-69.9)$ & $28.7(15.3-42.7)$ & 0.016 \\
\hline Volume of tumor, median (range) & & & \\
\hline Before treatment $\left(\mathrm{cm}^{3}\right)$ & $88.35(41.2-126)$ & $86.8(37.9-188.2)$ & 0.467 \\
\hline Before BT (cm $\left.{ }^{3}\right)$ & $20.8(11.1-47.4)$ & $33.2(18.9-109.1)$ & 0.034 \\
\hline Reduction (\%) & $75.1(48.4-94.8)$ & $62.4(42-81)$ & 0.001 \\
\hline EBRT, external beam radiation therapy; BT, brachytherapy. & & \\
\hline
\end{tabular}

\section{Safety}

Compression hemostasis was effective for all patients after the injection of H101. The most common adverse event related to $\mathrm{H} 101$ was fever (95\%). All adverse events that occurred during treatment are shown in Table 4. 
Table 4

Adverse events

\begin{tabular}{|lllll|}
\hline \multirow{2}{*}{ Events, $\mathbf{n}(\%)$} & H101 group (n= 20) & \\
\cline { 2 - 5 } & Grade 1 & Grade 2 & Grade 3 & Grade 4 \\
\hline Fever after H101 injection & $3(15)$ & $15(75)$ & $1(5)$ & 0 \\
\hline Pain due to injection & $2(10)$ & $1(5)$ & 0 & 0 \\
\hline Hematology & & & & \\
Leukopenia & 0 & $8(40)$ & $12(60)$ & 0 \\
\hline Neutropenia & $4(20)$ & $4(20)$ & $9(45)$ & $2(10)$ \\
\hline Thrombocytopenia & $7(35)$ & $5(25)$ & $1(5)$ & 0 \\
\hline Anemia & $1(15)$ & $8(40)$ & $8(40)$ & $3(15)$ \\
Fatigue & $14(70)$ & $1(5)$ & 0 & 0 \\
Diarrhea & $17(85)$ & $2(10)$ & $1(5)$ & 0 \\
\hline Nausea & $18(90)$ & $1(5)$ & 0 & 0 \\
\hline Vomiting & $2(10)$ & $1(5)$ & 0 & 0 \\
\hline
\end{tabular}

\section{Discussion}

Due to the poor prognosis of bulky LACC, studies exploring new treatment strategies are therefore highly important. The present study is the first of its kind focused on the treatment of bulky LACC with H101, a type of oncolytic virus, in combination with CCRT. The results demonstrate that $\mathrm{H} 101$ combined with CCRT plays a promising role with a high PFS (65\%) and OS (74.3\%) rate for a 3-year period.

The length of tumor over $6 \mathrm{~cm}$ is a significant predictor of poor prognosis for LACC after CCRT [12]. Endo et al [13]. reported that, in 85 patients with cervical cancer that all received CCRT including intracavitary BT, the 3-year OS rates of cervical cancer $\geq 6 \mathrm{~cm}$ after CCRT were $50.5 \%$ and $23.1 \%$, without and with enlarged pelvic lymph node, respectively. In another study, the median OS of patients with tumor $>6 \mathrm{~cm}$ was 38.3 months [14]. Wang et al [15] reported that the 3-year OS rate of cervical cancer patients with FIGO stage $\triangle \mathrm{B}$ and tumor length $>6 \mathrm{~cm}$ undergoing CCRT followed by intracavity BT was $42.9 \%$. In the present study, the length of cervical tumor $\geq 6 \mathrm{~cm}$ was a key criterion for recruitment, and there were 15 (75\%) and $16(80 \%)$ patients with pelvic and/or paraaortic lymph node metastasis in $\mathrm{H} 101$ group and control group, respectively. For control group, the 3-year PFS(43.8\%) and OS(54.5\%) rates were consistent

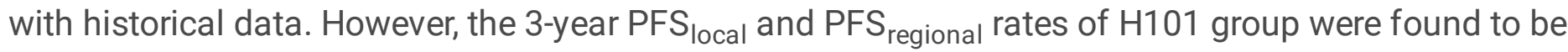
higher as compared with control group. This may be due to the fact that H101 in combination with CCRT shrank the tumor significantly during EBRT, thus creating a condition for BT to deliver a sufficient dose coverage for the whole tumor volume. Better trends of 3-year PFS and 3-year OS rates in $\mathrm{H} 101$ group 
could be observed in survival curve, however, there was no statistical difference between the two groups. This may be due to the small sample size.

BT plays an indispensable role in the radiotherapy of cervical cancer as it can provide local high-dose radiation, and the dose drops quickly to protect any adjacent organs at risk. Tumor size is the key factor affecting the efficacy of BT, since the coverage of high-dose BT is limited. It is difficult to deliver a sufficient dose to the whole bulky cervical tumor volume with intracavitary BT [16].

Intracavitary/interstitial BT can significantly improve the local control rate for bulky cervical tumor compared with intracavitary BT alone. However, intracavitary/interstitial BT requires more resources and skills to implement, which is unrealistic for massive deployment in developing countries where the incidence of bulky cervical cancer is high. An alternative strategy to improve BT efficacy is to minimize tumor size during EBRT. In the present study, H101 was added to CCRT, and intracavitary BT alone was performed to treat LACC patients. Following EBRT, the median tumor length was reduced from $6.6 \mathrm{~cm}$ to $4.1 \mathrm{~cm}$, and the median tumor volume was reduced from $88.35 \mathrm{~cm}^{3}$ to $20.8 \mathrm{~cm}^{3}$ for $\mathrm{H} 101$ group, the reduction of which was much more than that of control group. The small tumor after EBRT could be addressed by an adequate dose provided by intracavitary BT.

Oncolytic adenovirus $\mathrm{H} 101$ is characterized by the deletion of both E1B-55 kDa and $19 \mathrm{kDa}$ of E3 regions in the human adenovirus type 5 by means of genetic engineering technology. The $55 \mathrm{kDa}$ protein encoded by the E1B region of wild-type adenovirus gene can bind with the p53 protein to inhibit the clearance of adenovirus by $\mathrm{p} 53$ gene. The $\mathrm{H} 101$ virus cannot encode the E1B-55 kDa protein, thus it does not replicate in p53 normal cells. However, in tumor cells with abnormal p53 protein, $\mathrm{H} 101$ can replicate in large numbers because there is no inhibitory effect of p53. Thus, $\mathrm{H} 101$ can exert an oncolytic effect on tumor cells through the replicating virus, while it does not affect normal cells. The P53 gene mutation is widely found in many kinds of tumor. For cervical cancer that is associated with high-risk human papillomavirus (HPV) infection, some studies have demonstrated that the major transforming HPV E6 and E7 activities include the targeted degradation of $p 53[17,18]$. In this study, the rapid tumor regression may be associated with the p53 gene mutation and could be caused by the oncolytic effect of $\mathrm{H} 101$. Whether there is a synergistic effect between H101 and CCRT and the relevant mechanism needs to be further investigated. In addition, there are reasonable arguments that oncolytic adenoviruses may play be important in multi-stage immunotherapy $[19,20]$, therefore, the outlook of H101 combined with CCRT for tumor immunotherapy is highly promising.

In this study, treatment by intratumoral $\mathrm{H} 101$ injection combined with CCRT was well-tolerated. The adverse events were similar to those reported previously for $\mathrm{H} 101$ therapy $[5,7]$. The main adverse effect after $\mathrm{H} 101$ intratumoral injection was fever. Specifically, nineteen patients experienced this symptom and 18 of 19 had grade I to II fever. Three patients reported mild to moderate pain during the injection. Leukopenia, neutropenia, anemia, fatigue, diarrhea and nausea were also observed during treatment. However, these adverse effects were similar to those of CCRT previously reported for cervical cancer [2124]. Therefore, it was considered more likely that they were due to CCRT rather than intratumoral H101 injection. 
This study has several limitations. First, it was conducted in a single center with a small sample size. Second, there was no control group of patients receiving concurrent CCRT without the injection of H101, therefore, the data were compared with retrospective and historical control without $\mathrm{H} 101$. Third, molecular analysis was not performed to explore the mechanism of $\mathrm{H} 101$ effect on cervical cancer and its relationship with CCRT.

\section{Conclusions}

In conclusion, the intratumoral injection of recombinant human type 5 adenovirus $\mathrm{H} 101$ in combination with CCRT has promising efficacy for LACC patients, and has an acceptable safety profile. Randomized controlled trials are warranted to confirm the present results.

\section{List Of Abbreviations}

Adverse effects (AEs); Brachytherapy (BT); Chinese Food and Drug Administration (CFDA); computed tomography (CT); Concurrent chemoradiotherapy (CCRT); External beam radiotherapy (EBRT); International Federation of Gynecology and Obstetrics (FIGO); Locally advanced cervical cancer (LACC); Normal saline (NS); Overall survival (OS); Progression-free survival (PFS).

\section{Declarations}

\section{Ethics approval and consent to participate}

The study was conducted in accordance with the Declaration of Helsinki and Good Clinical Practice, approved by the Ethics Committee of Zhejiang Cancer Hospital, and registered at Chinese Clinical Trail Registry (ChiCTR-OPC-15006142). All participating patients gave their written informed consent for taking part in the study.

\section{Consent for publication}

All authors have approved publication of the paper.

\section{Availability of data and materials}

All data generated or analyzed during this study could be obtained upon reasonable request to the corresponding author.

\section{Competing interests}

The authors declare that they have no competing interests.

\section{Funding}


Project supported by the Zhejiang Natural Science Foundation (No. LY17H160037); the Zhejiang Traditional Chinese Medicine Administration Project (No. 2015ZB018); and the Zhejiang Medicine and Health Science and Technology Project (No. 2018KY299).

\section{Author contribution}

Xiangzhang, Drafting of the manuscript, Statistical analysis and Interpretation of data.

Yingchang Wang, Acquisition of data, Drafting of the manuscript.

Xiaojuan Lv, Acquisition of data, Drafting of the manuscript.

Fangfang Wang, Critical revision of the manuscript for important intellectual content.

Qiong Zhou, Critical revision of the manuscript for important intellectual content.

Feiya Zhang, Acquisition of data.

Meng Zhang, Acquisition of data.

Jianhong Chen, Study design, Critical revision of the manuscript for important intellectual content.

\section{Acknowledgements}

None.

\section{References}

1. Arbyn M, Weiderpass E, Bruni L, de Sanjose S, Saraiya M, Ferlay J, et al. Estimates of incidence and mortality of cervical cancer in 2018: a worldwide analysis. The Lancet Global health. 2020;8:e191e203.

2. Chen W, Zheng R, Baade PD, Zhang S, Zeng H, Bray F, et al. Cancer statistics in China, 2015. CA: a cancer journal for clinicians. 2016;66:115-32.

3. Cho 0, Chun M. Management for locally advanced cervical cancer: new trends and controversial issues. Radiation oncology journal. 2018;36:254-64.

4. Liang M. Oncorine, the World First Oncolytic Virus Medicine and its Update in China. Current cancer drug targets. 2018;18:171-6.

5. Lu YK HX, Li FX, Liu ZH, Li YQ, Yang YL. Radiotherapy combined with chemotherapy and intratumoral injection of EIB gene-deleted adenovirus(H101) for nasopharyngeal carcinoma. Zhong Liu. 2006;26:453-5.

6. He CB, Lao XM, Lin XJ. Transarterial chemoembolization combined with recombinant human adenovirus type $5 \mathrm{H} 101$ prolongs overall survival of patients with intermediate to advanced hepatocellular carcinoma: a prognostic nomogram study. Chinese journal of cancer. 2017;36:59. 
7. He Q, Liu Y, Zou Q, Guan YS. Transarterial injection of H101 in combination with chemoembolization overcomes recurrent hepatocellular carcinoma. World journal of gastroenterology. 2011;17:2353-5.

8. Lin XJ, Li QJ, Lao XM, Yang H, Li SP. Transarterial injection of recombinant human type-5 adenovirus H101 in combination with transarterial chemoembolization (TACE) improves overall and progressivefree survival in unresectable hepatocellular carcinoma (HCC). BMC cancer. 2015;15:707.

9. Zhu Q XK, Fu H, Wu ZY, He YP, Chen X. EUS-guided oncolytic adenovirus implantation in patients of non-operative pancreatic cancer. Zhong Hua Xiao Hua Nei Jing Za Zhi. 2008;25:341-6.

10. Zhou CC XY, Ni J, Zhou SW, Xu JF, Lv MJ. Oncolytic adenovirus H101 in combination with vinorelbine/cisplatin chemotherapy for advanced non-small cell lung cancer. Zhong Liu. 2006;26.

11. Xiao B JZ, Li ZS, Du YQ, Wu RP, Zhou J. Intra-tumoral injection of E1B gene-deleted adenovirus combined with gemcitabine for unresectable pancreatic carcinoma. Zhong Hua Yi Xian Bing Za Zhi. 2011;11:163-6.

12. Kapp KS, Stuecklschweiger GF, Kapp DS, Poschauko J, Pickel H, Lahousen M, et al. Prognostic factors in patients with carcinoma of the uterine cervix treated with external beam irradiation and IR192 high-dose-rate brachytherapy. International journal of radiation oncology, biology, physics. 1998;42:531-40.

13. Endo D, Todo Y, Okamoto K, Minobe S, Kato H, Nishiyama N. Prognostic factors for patients with cervical cancer treated with concurrent chemoradiotherapy: a retrospective analysis in a Japanese cohort. Journal of gynecologic oncology. 2015;26:12-8.

14. Kyung MS, Kim HB, Seoung JY, Choi IY, Joo YS, Lee MY, et al. Tumor size and lymph node status determined by imaging are reliable factors for predicting advanced cervical cancer prognosis. Oncology letters. 2015;9:2218-24.

15. Wang N, Li WW, Li JP, Liu JY, Zhou YC, Zhang Y, et al. Comparison of concurrent chemoradiotherapy followed by radical surgery and high-dose-rate intracavitary brachytherapy: a retrospective study of 240 patients with FIGO stage IIB cervical carcinoma. OncoTargets and therapy. 2014;7:91-100.

16. Fokdal L, Sturdza A, Mazeron R, Haie-Meder C, Tan LT, Gillham C, et al. Image guided adaptive brachytherapy with combined intracavitary and interstitial technique improves the therapeutic ratio in locally advanced cervical cancer: Analysis from the retroEMBRACE study. Radiotherapy and oncology : journal of the European Society for Therapeutic Radiology and Oncology. 2016;120:43440.

17. Dyson N, Howley PM, Munger K, Harlow E. The human papilloma virus-16 E7 oncoprotein is able to bind to the retinoblastoma gene product. Science. 1989;243:934-7.

18. Scheffner M, Werness BA, Huibregtse JM, Levine AJ, Howley PM. The E6 oncoprotein encoded by human papillomavirus types 16 and 18 promotes the degradation of p53. Cell. 1990;63:1129-36.

19. Peter M, Kuhnel F. Oncolytic Adenovirus in Cancer Immunotherapy. Cancers. 2020;12.

20. Huang H, Liu Y, Liao W, Cao Y, Liu Q, Guo Y, et al. Oncolytic adenovirus programmed by synthetic gene circuit for cancer immunotherapy. Nature communications. 2019;10:4801. 
21. Jakubowicz J, Blecharz P, Skotnicki P, Reinfuss M, Walasek T, Luczynska E. Toxicity of concurrent chemoradiotherapy for locally advanced cervical cancer. European journal of gynaecological oncology. 2014;35:393-9.

22. Wang W, Hou X, Yan J, Shen J, Lian X, Sun S, et al. Outcome and toxicity of radical radiotherapy or concurrent Chemoradiotherapy for elderly cervical cancer women. BMC cancer. 2017;17:510.

23. Song S, Rudra S, Hasselle MD, Dorn PL, Mell LK, Mundt AJ, et al. The effect of treatment time in locally advanced cervical cancer in the era of concurrent chemoradiotherapy. Cancer. 2013;119:32531.

24. Rose PG, Bundy BN, Watkins EB, Thigpen JT, Deppe G, Maiman MA, et al. Concurrent cisplatin-based radiotherapy and chemotherapy for locally advanced cervical cancer. The New England journal of medicine. 1999;340:1144-53.

\section{Figures}

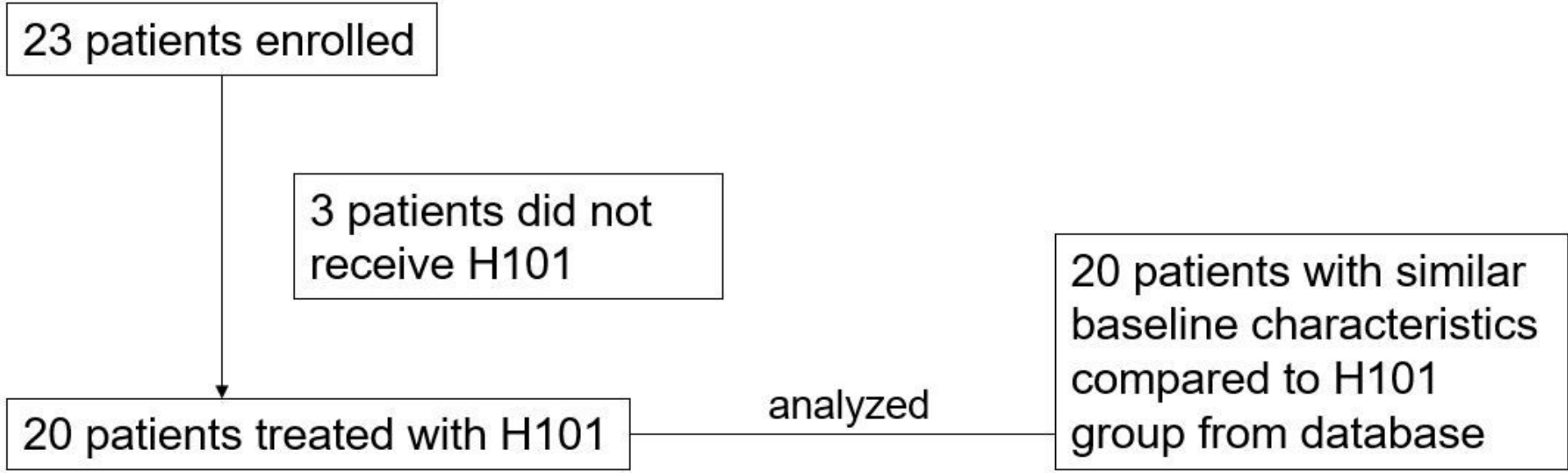

Figure 1

Patient baseline characteristics. 

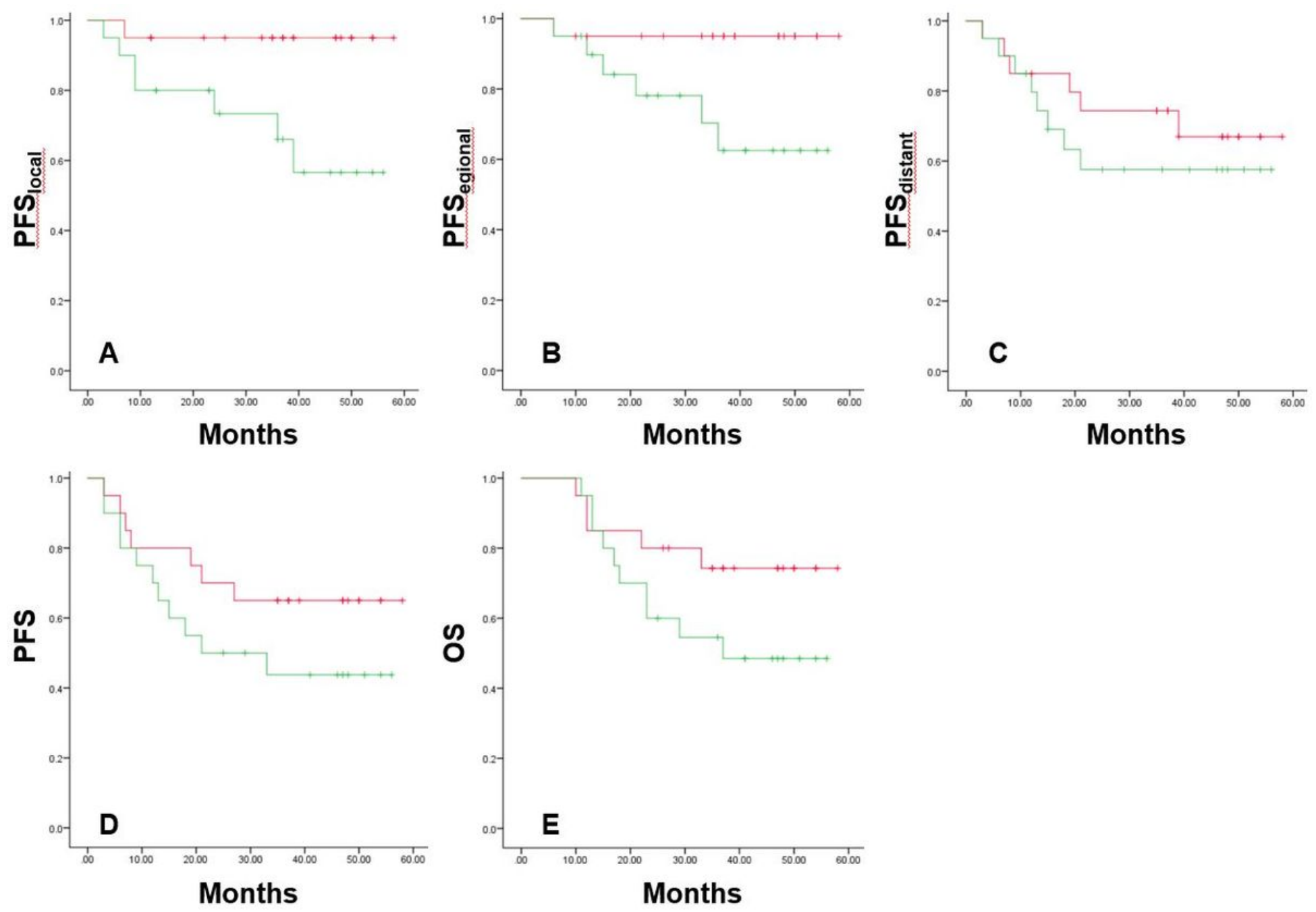

Figure 2

The 3-year local, regional, distant and overall PFS rates were $95 \%$ vs $66.6 \%(p=0.02), 95 \%$ vs $62.5 \%(p=$ $0.029), 74.4 \%$ vs $57.6(p=0.428)$ and $65 \%$ vs $43.8 \%(p=0.19)$, for $\mathrm{H} 101$ group and control group respectively. The 3-year overall survival (OS) for $\mathrm{H} 101$ group and control group were $74.3 \%$ vs $54.5 \%(\mathrm{p}=$ 0.098), respectively. 